\title{
Association between commercial television exposure and fast-food consumption among adults
}

\author{
Maree Scully*, Helen Dixon and Melanie Wakefield \\ Centre for Behavioural Research in Cancer, The Cancer Council Victoria, 1 Rathdowne Street, Carlton, \\ Victoria 3053, Australia
}

Submitted 20 February 2007: Accepted 2 February 2008: First published online 14 March 2008

\begin{abstract}
Objective: To examine the association between television advertising exposure and adults' consumption of fast foods.

Design: Cross-sectional telephone survey. Questions included measures of frequency of fast-food consumption at different meal times and average daily hours spent watching commercial television.

Subjects/setting: Subjects comprised 1495 adults ( $41 \%$ response rate) aged $\geq 18$ years from Victoria, Australia.

Results: Twenty-three per cent of respondents usually ate fast food for dinner at least once weekly, while $17 \%$ consumed fast food for lunch on a weekly basis. The majority of respondents reported never eating fast food for breakfast (73\%) or snacks $(65 \%)$. Forty-one per cent of respondents estimated watching commercial television for $\leq 1 \mathrm{~h} / \mathrm{d}$ (low viewers); $29 \%$ watched for $2 \mathrm{~h} / \mathrm{d}$ (moderate viewers); $30 \%$ watched for $\geq 3 \mathrm{~h} / \mathrm{d}$ (high viewers). After adjusting for demographic variables, high viewers were more likely to eat fast food for dinner at least once weekly compared with low viewers (OR $=1 \cdot 45 ; 95 \%$ CI $1 \cdot 04,2 \cdot 03)$. Both moderate viewers $(\mathrm{OR}=1 \cdot 53 ; 95 \% \mathrm{CI} 1 \cdot 01,2 \cdot 31)$ and high viewers $(\mathrm{OR}=1 \cdot 81$; $95 \%$ CI $1 \cdot 20,2 \cdot 72$ ) were more likely to eat fast food for snacks at least once weekly compared with low viewers. Commercial television viewing was not significantly related $(P>0 \cdot 05)$ to fast-food consumption at breakfast or lunch. Conclusions: The results of the present study provide evidence to suggest that cumulative exposure to television food advertising is linked to adults' fast-food consumption. Additional research that systematically assesses adults' behavioural responses to fast-food advertisements is needed to gain a greater understanding of the mechanisms driving this association.
\end{abstract}

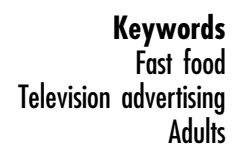

Fast-food companies are among the biggest advertisers in Australia. In 2005, it was estimated that this industry spent upwards of AU\$110 million promoting their brands across mainstream media ${ }^{(1)}$. McDonald's was the top fast-food company advertiser, lifting its yearly activity by $26 \%$ to an estimated AU\$50 million ${ }^{(1)}$. The heavy marketing by fastfood companies is reflected on our television screens. A recent comprehensive content analysis of food advertising on Australian commercial television indicated that viewers are exposed to an average of five food advertisements per hour, with fast food and takeaway (30\%) the most advertised food category ${ }^{(2)}$.

The impact of television food advertising on children has received considerable attention in the research literature, with a number of studies finding evidence to suggest that advertising affects children's food preferences and their purchase requests, and that greater television use is positively associated with children's consumption of energy-dense foods ${ }^{(3,4)}$. However, there is less published data on how television viewing may influence adults' dietary behaviour.

Previous research indicates there is a positive relationship between hours of television viewing and adult obesity $^{(5)}$. For example, a cross-sectional study of overweight and obesity in Australia found a strong effect of television viewing time on two measures of obesity - BMI and waist circumference - in both men and women, after adjusting for physical activity and other risk factors ${ }^{(6)}$. One possible contributor to the television-obesity link is that people may tend to eat more when watching television. An experiment conducted by Blass et al. revealed an increase in college students' intake of energy-dense foods during television viewing ${ }^{(7)}$. Hours of television viewing has also been shown to be positively associated with energy intake among high- and low-income women, but not men ${ }^{(8)}$. 
Two studies have looked at the correlation between eating at fast-food restaurants and television viewing. Among a sample of adult women, more frequent fastfood restaurant users reported spending the most time watching television ${ }^{(9)}$. A trend for television viewing to be associated with eating at a fast-food restaurant at least once weekly was observed in a later study of adults ${ }^{(10)}$.

Research conducted among children has identified food advertising as a likely mediating influence in the link between television viewing and poor dietary practices ${ }^{(4)}$. The aim of the present study was to examine the association between television advertising exposure and adults' consumption of fast foods. In Australia, adults who routinely watch commercial television are potentially exposed to a large amount of fast-food advertising, with an average of one-and-a-half advertisements per hour promoting these types of foods ${ }^{(2)}$. Consequently, it was hypothesised that commercial television viewing would be positively associated with fast-food consumption.

\section{Methods}

\section{Procedure}

During April and May 2005, a market research company conducted a telephone survey of a representative sample of Victorian adults, aged $\geq 18$ years, on behalf of The Cancer Council Victoria. The sample was stratified by Melbourne metropolitan and rural Victoria according to the population distribution (approximately 70\%:30\%). The sampling frame for the survey was the Electronic White Pages telephone directory.

A generic approach letter introducing the survey (on the market research company's letterhead) was sent to the household of each randomly selected telephone number. Up to six calls were made to establish initial contact; however, once contact was established, the number of further attempts to achieve an interview was unlimited. When the household was contacted, the person who had their birthday next and was aged 18 years or older was selected for the interview.

\section{Questionnaire}

The questionnaire was a multi-purpose survey developed by the Centre for Behavioural Research in Cancer of The Cancer Council Victoria. Owing to the large number of questions covered in the survey, some questions were asked of a random sample comprising half the survey population. Thus, for the present paper, a total of 1495 people were asked a series of questions about their fastfood consumption and television viewing habits.

To assess fast-food consumption, respondents were asked to indicate how often over the past three months they had eaten fast food at breakfast, lunch and dinner, and for snacks, respectively. Examples of fast foods provided to respondents were McDonalds, KFC, Pizza Hut, hamburgers, hot chips, pies, pasties, sausage rolls or deep-fried foods. These chosen foods are comparable to the categories of fast food applied in Australian content analyses of television food advertising ${ }^{(2,11,12)}$. Responses were recorded on an 8-point scale ranging from 'nearly every day' through to 'never'. As fast foods are generally high in fat, salt and/or sugar, they should only be eaten sometimes and in small amounts ${ }^{(13)}$. In line with a previous study that looked at factors associated with eating fast food ${ }^{(10)}$, responses to each item were dichotomised as follows: less than once weekly $(=0)$ and at least once weekly $(=1)$.

A proxy measure of adults' exposure to television advertisements was determined by asking respondents to estimate their level of commercial television viewing. Focusing on commercial television viewing as opposed to overall television viewing ensured that only television providing potential advertising exposure was included. Given the limited space available in the survey, the following single item measure, adapted from Jeffrey and French $^{(8)}$, was used: 'On average, how many hours per day do you usually spend watching commercial television?' (i.e. Channel 7, 9, 10, SBS). Response options were integers ranging from 0 to $24 \mathrm{~h}$. Two cases were excluded, as the reported hours spent watching all television was deemed implausible ( 19 and $21 \mathrm{~h} / \mathrm{d}$ ). As this variable was excessively skewed, responses were collapsed into the following categories: $\leq 1 \mathrm{~h}$ (low viewers); $2 \mathrm{~h}$ (moderate viewers); $\geq 3$ h (high viewers).

Respondents were asked to self-report their height and weight in order to calculate BMI as weight $(\mathrm{kg}) /$ height $(\mathrm{m})]^{2}$. Based on the WHO classifications ${ }^{(14)}$, BMI of $<18.5 \mathrm{~kg} / \mathrm{m}^{2}$ was considered underweight, BMI of $18.5-24.9 \mathrm{~kg} / \mathrm{m}^{2}$ was considered healthy weight, BMI of $25 \cdot 0-29 \cdot 9 \mathrm{~kg} / \mathrm{m}^{2}$ was regarded as overweight, and BMI of $\geq 30 \cdot 0 \mathrm{~kg} / \mathrm{m}^{2}$ was considered obese.

Demographic variables recorded included age, gender, level of education, and whether the respondent resided in a metropolitan or rural area. A measure of socioeconomic status (SES) was determined according to the urban index of relative advantage/disadvantage as described by the Australian Bureau of Statistics ${ }^{(15)}$, based on respondent's home postcode. Using the Victorian quartile values, respondents were categorised into the following SES groups: low, lower middle, upper middle and high.

\section{Data analyses}

Analysis was undertaken using the Statistical Package for the Social Sciences statistical software package version 14 (SPSS Inc., Chicago, IL, USA). A comparison of the sample's sociodemographic characteristics with the Australian Bureau of Statistics' estimates of the Victorian population revealed that women were over-represented. As a result, 
responses were weighted by age and gender according to the Victorian population ${ }^{(16)}$. The prevalence estimates reported in the present paper were based on these weighted data.

Logistic regression analyses examined the association between eating fast food at least once weekly at different meal times and commercial television viewing, with low viewers $(\leq 1 \mathrm{~h} / \mathrm{d})$ as the reference group. Demographic variables including gender, age group, level of education, location and SES were controlled for in these analyses.

\section{Results}

\section{Response rate}

Overall, 10971 Victorian records were randomly selected from the Electronic White Pages telephone directory. Where possible, approach letters were mailed to households prior to attempting telephone contact. However, due to budgeting and scheduling restraints, $22 \%$ of potential respondents were contacted only via telephone. Of the 7372 (67\%) households that were contacted and eligible, 3001 interviews were completed, yielding a response rate of $41 \%$. Half of these interviews ( $n$ 1495) included questions on fast-food consumption and television viewing habits.

\section{Body weight, fast-food consumption and commercial television viewing}

Nearly one-third (31\%) of respondents were found to be overweight, while a further $13 \%$ were obese. Approximately half of the respondents (53\%) had BMI within the healthy weight range and $2 \%$ were underweight.

As illustrated in Table 1, the majority of respondents indicated that they do not eat fast food for breakfast (73\%) or snacks (65\%). Twenty-three per cent of respondents consumed fast food for dinner at least once weekly, while one-third (33\%) ate fast food for dinner on a fortnightly or monthly basis. Seventeen per cent reported consuming fast food for lunch at least once weekly, yet $42 \%$ of respondents said they never ate fast food for lunch.

Overall, $41 \%$ of respondents indicated that they usually watch commercial television for $\leq 1 \mathrm{~h} / \mathrm{d}$. Twenty-nine per cent estimated doing this activity for $2 \mathrm{~h} / \mathrm{d}$, while a

Table 1 Fast-food consumption of Victorian adults at different meal times (\%)

\begin{tabular}{lcccr}
\hline Frequency & Breakfast & Lunch & Dinner & Snacks \\
\hline At least once weekly & $4 \cdot 8$ & $17 \cdot 0$ & $22 \cdot 6$ & $12 \cdot 1$ \\
Fortnightly or monthly & $8 \cdot 6$ & $25 \cdot 5$ & $33 \cdot 2$ & $13 \cdot 8$ \\
Less than once monthly & $13 \cdot 4$ & $15 \cdot 6$ & $17 \cdot 8$ & $9 \cdot 6$ \\
Never & $73 \cdot 2$ & $41 \cdot 8$ & $26 \cdot 4$ & $64 \cdot 6$ \\
\hline
\end{tabular}

Proportions are based on weighted data. further $30 \%$ reported watching commercial television for $\geq 3 \mathrm{~h} / \mathrm{d}$.

\section{Relationship between fast-food consumption and commercial television viewing}

Table 2 presents results from separate multivariate logistic regression analyses examining associations between respondents' fast-food consumption at different meal times (breakfast, lunch, dinner, snacks) and their commercial television use, after adjusting for demographic variables (gender, age group, level of education, location, SES).

Respondents who watched commercial television for $\geq 3 \mathrm{~h} / \mathrm{d}$ were significantly more likely to eat fast food for dinner at least once weekly compared with those who watched for $\leq 1 \mathrm{~h} / \mathrm{d}(\mathrm{OR}=1 \cdot 45 ; 95 \%$ CI 1·04, 2·03). Time spent watching commercial television was positively associated with the consumption of fast foods for snacks. Respondents were significantly more likely to report eating fast foods for snacks at least once weekly if they usually watched commercial television for $2 \mathrm{~h} / \mathrm{d}(\mathrm{OR}=$ $1 \cdot 53 ; 95 \%$ CI $1 \cdot 01,2 \cdot 31)$ or $\geq 3 \mathrm{~h} / \mathrm{d}(\mathrm{OR}=1 \cdot 81 ; 95 \% \mathrm{CI}$ $1 \cdot 20,2 \cdot 72)$. There was no significant relationship between commercial television viewing and fast-food consumption at breakfast or lunch (both $P>0.05$ ).

Some significant demographic associations with fastfood consumption were evident. Notably, fast-food consumption decreased with age across all meal times (see Table 2). Also, females were less likely than males to eat fast food at least once weekly for breakfast $(\mathrm{OR}=0 \cdot 40$; $95 \%$ CI $0 \cdot 23,0 \cdot 67)$, lunch $(\mathrm{OR}=0 \cdot 61 ; 95 \%$ CI $0 \cdot 46,0 \cdot 82)$ and snacks $(\mathrm{OR}=0.54 ; 95 \% \mathrm{CI} 0 \cdot 38,0 \cdot 75)$.

\section{Discussion}

The results of the present study provide evidence to suggest that cumulative exposure to television food advertising is linked to adults' fast-food consumption. Consistent with our hypothesis, commercial television viewing was positively associated with eating fast food at least once weekly for dinner and snacks. However, a similar effect for frequency of fast-food consumption for breakfast or lunch was not found.

One possible explanation for this pattern of results is the varying concentration of fast-food advertising on Australian television throughout the day. Advertisements for fast food and takeaway occur at a higher rate late in the day, with people watching television in the evening (18.00-21.00 hours) exposed, on average, to double the number of fast-food and takeaway advertisements than people watching television between 07.00 and 09.00 hours $^{(2)}$. Fast-food and takeaway advertisements aired in the evening also have the potential to reach a higher audience; approximately $40 \%$ of people are watching television during this peak viewing period while less than 
Table 2 Results of logistic regression modelling of variables associated with eating fast food at least once weekly at different meal times

\begin{tabular}{|c|c|c|c|c|c|c|c|c|}
\hline \multirow[b]{3}{*}{ Variable } & \multicolumn{8}{|c|}{ Fast food at least once weekly } \\
\hline & \multicolumn{2}{|c|}{ Breakfast } & \multicolumn{2}{|c|}{ Lunch } & \multicolumn{2}{|c|}{ Dinner } & \multicolumn{2}{|c|}{ Snacks } \\
\hline & Adjusted ORt & $95 \% \mathrm{Cl}$ & Adjusted ORt & $95 \% \mathrm{Cl}$ & Adjusted ORt & $95 \% \mathrm{Cl}$ & Adjusted ORt & $95 \% \mathrm{Cl}$ \\
\hline \multicolumn{9}{|l|}{ Gender } \\
\hline Male & $1 \cdot 00$ & & $1 \cdot 00$ & & $1 \cdot 00$ & & $1 \cdot 00$ & \\
\hline Female & $0 \cdot 40^{\star \star}$ & $0.23,0.67$ & $0 \cdot 61^{\star \star}$ & $0.46,0.82$ & $0 \cdot 83$ & $0.63,1 \cdot 08$ & $0 \cdot 54^{\star \star \star}$ & $0.38,0.75$ \\
\hline \multicolumn{9}{|l|}{ Age (years) } \\
\hline $18-29$ & $1 \cdot 00$ & & $1 \cdot 00$ & & $1 \cdot 00$ & & $1 \cdot 00$ & \\
\hline $30-44$ & $0 \cdot 28^{\star \star *}$ & $0 \cdot 15,0 \cdot 51$ & $0 \cdot 58^{\star \star}$ & $0 \cdot 42,0.82$ & $0 \cdot 74$ & $0.53,1.03$ & $0 \cdot 52^{\star \star}$ & $0.35,0.78$ \\
\hline $45-59$ & $0 \cdot 14^{\star \star \star}$ & $0.06,0.32$ & $0 \cdot 26^{\star \star \star}$ & $0.17,0.40$ & $0 \cdot 49^{\star \star \star}$ & $0.33,0.72$ & $0 \cdot 25^{\star \star \star}$ & $0.15,0.42$ \\
\hline$\geq 60$ & $0.05^{\star \star \star}$ & $0 \cdot 01,0.17$ & $0.07^{\star \star \star}$ & $0 \cdot 03,0.13$ & $0.09^{\star \star \star}$ & $0 \cdot 05,0 \cdot 17$ & $0 \cdot 10^{\star \star \star}$ & $0.05,0.19$ \\
\hline \multicolumn{9}{|l|}{ Level of education } \\
\hline Year 9 or below & $1 \cdot 00$ & & $1 \cdot 00$ & & $1 \cdot 00$ & & $1 \cdot 00$ & \\
\hline Year 10 or 11 & 1.37 & $0 \cdot 50,3 \cdot 71$ & $0 \cdot 87$ & $0 \cdot 49,1 \cdot 55$ & $0 \cdot 89$ & $0.51,1.54$ & $0 \cdot 81$ & $0.45,1.47$ \\
\hline Year 12 & $0 \cdot 62$ & $0 \cdot 23,1 \cdot 66$ & $0 \cdot 81$ & $0 \cdot 47,1 \cdot 39$ & 0.93 & $0.55,1.57$ & $0 \cdot 60$ & $0.34,1.06$ \\
\hline Tertiary degree & $0 \cdot 80$ & $0 \cdot 29,2 \cdot 21$ & $0.53^{\star}$ & $0.30,0.95$ & 0.64 & $0 \cdot 37,1 \cdot 10$ & $0 \cdot 34^{\star \star}$ & $0.18,0.64$ \\
\hline \multicolumn{9}{|l|}{ Location } \\
\hline Metropolitan & $1 \cdot 00$ & & $1 \cdot 00$ & & $1 \cdot 00$ & & $1 \cdot 00$ & \\
\hline Rural & $1 \cdot 21$ & $0 \cdot 64,2 \cdot 29$ & $0 \cdot 83$ & $0 \cdot 56,1 \cdot 22$ & 0.94 & $0 \cdot 66,1 \cdot 33$ & $0 \cdot 80$ & $0.52,1 \cdot 23$ \\
\hline \multicolumn{9}{|l|}{ SES } \\
\hline Low & $1 \cdot 00$ & & $1 \cdot 00$ & & $1 \cdot 00$ & & $1 \cdot 00$ & \\
\hline Lower middle & $0 \cdot 26^{\star \star}$ & $0 \cdot 10,0 \cdot 72$ & $0 \cdot 78$ & $0 \cdot 46,1 \cdot 34$ & $1 \cdot 35$ & $0 \cdot 83,2 \cdot 20$ & $0 \cdot 78$ & $0.45,1.37$ \\
\hline Upper middle & 0.68 & $0 \cdot 34,1 \cdot 33$ & 0.97 & $0.62,1.52$ & $1 \cdot 26$ & $0 \cdot 82,1.95$ & $0 \cdot 72$ & $0 \cdot 44,1 \cdot 18$ \\
\hline High & $0 \cdot 36^{\star}$ & $0 \cdot 17,0.78$ & $0 \cdot 78$ & $0 \cdot 48,1 \cdot 25$ & 0.93 & $0.59,1.48$ & 0.60 & $0.35,1.01$ \\
\hline \multicolumn{9}{|c|}{ Commercial TV viewing } \\
\hline$\leq 1 \mathrm{~h} / \mathrm{d}$ & 1.00 & & $1 \cdot 00$ & & $1 \cdot 00$ & & $1 \cdot 00$ & \\
\hline $2 \mathrm{~h} / \mathrm{d}$ & $1 \cdot 04$ & $0.56,1.93$ & $1 \cdot 16$ & $0 \cdot 82,1 \cdot 65$ & $1 \cdot 33$ & $0.95,1 \cdot 86$ & $1 \cdot 53^{\star}$ & $1 \cdot 01,2 \cdot 31$ \\
\hline$\geq 3 \mathrm{~h} / \mathrm{d}$ & $1 \cdot 21$ & $0 \cdot 66,2 \cdot 23$ & $1 \cdot 08$ & $0 \cdot 76,1 \cdot 55$ & $1 \cdot 45^{\star}$ & $1 \cdot 04,2 \cdot 03$ & $1 \cdot 81^{\star *}$ & $1 \cdot 20,2 \cdot 72$ \\
\hline
\end{tabular}

SES, socio-economic status; TV, television.

Odds ratios were significant: ${ }^{*} P<0.05,{ }^{\star *} P<0.01,{ }^{\star \star *} P<0.001$.

tAdjusted for all other variables in the model.

$10 \%$ of people are watching in the early morning ${ }^{(17)}$. Thus, larger 'doses' of exposure to fast-food advertisements may act as a stronger cue to engage in the advertised eating behaviour. A possible dose-response relationship is consistent with results from an experimental study conducted with US pre-school children, which found that children who viewed a video with food advertisements embedded were more likely to choose the advertised brands compared with children in the control condition, with stronger effects detected if the food advertisement was seen twice ${ }^{(18)}$. Advertising for other health-hazardous products has also been found to be positively associated with their consumption. For example, a meta-analysis exploring the determinants of cigarette consumption observed a positive relationship between cigarette advertising expenditure and cigarette demand (which primarily reflects cigarette consumption among adults) ${ }^{(19)}$

The lack of effect of commercial television viewing on fast-food consumption at breakfast and lunch may also be due to the time lag associated with exposure to fast-food advertising and eating behaviour at these meal times. With television viewing and airing of fast-food advertisements peaking in the evening, the process of being motivated to purchase and consume fast food for breakfast or lunch after watching commercial television will commonly be interrupted by sleep. In contrast, the planning of dinner may often coincide with television viewing, thus providing a clearer and shorter pathway for effects to occur.

Another possible contributing factor towards the absence of an association between commercial television viewing and fast-food consumption at breakfast and lunch may have been our reduced power to detect small differences. In general, consumption of fast food at least once weekly at the four specified meal times was relatively low in our sample, ranging from $23 \%$ at dinner to just $5 \%$ at breakfast. This meant that the cell sizes for some of our analyses were less than optimal. That we were still able to observe positive effects of commercial television viewing on frequency of eating fast food for snacks and dinner despite this limitation suggests that these relationships are robust.

The combined prevalence of overweight and obesity in our sample was relatively low (45\%), with the most recent national data indicating that nearly $60 \%$ of Australian adults aged 25 years and over are overweight or obese $^{(6)}$. This discrepancy is likely due to our reliance on self-reported measures of height and weight to calculate respondents' BMI status. Previous studies indicate that levels of overweight and obesity are underestimated when based on self-reported data, with people typically overestimating their height and underestimating their weight $^{(20-22)}$. People's tendency to portray themselves in 
the most favourable light may have also led to respondents under-reporting their fast-food consumption and commercial television viewing. However, we would expect that such a social desirability bias would have weakened rather than strengthened the observed associations.

The apparent link between television advertising exposure and adults' fast-food consumption does raise some interesting considerations for obesity prevention. In Australia, there have been widespread calls to ban 'junk' food advertising during children's programming in response to escalating obesity rates among young peo$\mathrm{ple}^{(23,24)}$. The results of the present study indicate that we should not discount the influence that television advertising may have on adult dietary behaviour. Despite fast foods not being recommended for regular consumption due to their typically high fat and salt content ${ }^{(13)}$, nearly one-third of all food advertisements aired promote these products $^{(2)}$. With research indicating that fast-food consumption is related to increased body weight ${ }^{(8,9)}$, greater effort needs to be directed at reducing the intake of these types of foods. Strategies such as restricting the amount of fast-food advertising on television and raising public awareness of the health consequences of regularly eating fast-food items, particularly among males and younger adults who are more likely to be frequent consumers, could be beneficial.

Some study limitations should be noted. Owing to the cross-sectional design of the study, a causal effect of commercial television viewing on fast-food consumption cannot be inferred. It is possible that other factors may mediate this relationship, such as increased snacking while watching television or individuals with less healthy eating habits being more inclined towards watching television.

While a strength of the present study is that it employed a more specific measure of television advertising exposure by looking at commercial television viewing practices as opposed to overall hours spent watching television, there are problems with this measurement. First, it is unable to differentiate between people who attended to the advertisements and those who completed other tasks during programme breaks. Second, it does not take into account the time of day in which viewing occurred which, as content analyses highlight, can impact on the types of food advertisements seen by viewers. Improving the precision of measuring exposure to fastfood advertisements in future studies may assist in providing stronger evidence of an association with fast-food consumption.

The relatively narrow definition of fast food applied in the present study was also a limitation. Although the examples provided to respondents were comparable to the categories of fast food used in Australian content analyses of television food advertising ${ }^{(2,11,12)}$, they were mainly focused on hot, meal-type foods and did not take into account cold, snack-type fast-food options such as doughnuts, ice creams and sweet pastries. Thus, adopting a broader definition of fast food may have led to higher estimates of consumption, in particular for breakfast, snacks and lunch, and by extension a greater capacity to observe relationships with commercial television viewing.

A further limitation of the study was the relatively low response rate $(41 \%)$. This reflects a growing decline in levels of participation in both epidemiology and survey research $^{(25,26)}$. The potential negative impact of the low response rate was minimised, however, by weighting the sample by the age and gender of the Victorian population.

With the growing prevalence of overweight and obesity in the community, identifying factors that may be contributing to this epidemic is vital. The present study indicates that the link between television food advertising exposure and adult fast-food consumption is one such factor that warrants further scrutiny. Additional research that systematically assesses adults' behavioural responses to fast-food advertisements is needed to gain a greater understanding of the mechanisms driving this association.

\section{Acknowledgements}

The study was funded by The Cancer Council Victoria. We gratefully acknowledge the contribution of Melissa Cameron in coordinating the fieldwork and David Crawford in providing input on question design and valuable comments and suggestions. M.S. analysed the data and wrote the first draft of the paper. H.D. and M.W. conceived and designed the study. All authors interpreted the data and were involved in revising the paper. No conflicting interests declared.

\section{References}

1. Nielsen Media Research (2006) Australia's top advertisers. http://www.nielsenmedia.com.au/files/ADNEWSTOP\%20 ADVERTISERS2005.pdf (accessed November 2006).

2. Chapman K, Nicholas P \& Supramaniam R (2006) How much food advertising is there on Australian television? Health Promot Int 21, 172-180.

3. Coon KA \& Tucker KL (2002) Television and children's consumption patterns: a review of the literature. Minerva Pediatr 54, 423-436.

4. Hastings G, Stead M, McDermott L, Forsyth A, MacKintosh AM, Rayner M, Godfrey C, Caraher M \& Angus K (2003) Review of research on the effects of food promotion to children. http://www.foodstandards.gov.uk/multimedia/ pdfs/foodpromotiontochildren1.pdf (accessed February 2004).

5. Foster JA, Gore SA \& Smith West D (2006) Altering TV viewing habits: an unexplored strategy for adult obesity intervention? Am J Health Behav 30, 3-14.

6. Cameron AJ, Welborn TA, Zimmet PZ, Dunstan DW, Owen N, Salmon J, Dalton M, Jolley D \& Shaw JE (2003) 
Overweight and obesity in Australia: The 1999-2000 Australian Diabetes, Obesity and Lifestyle Study (AusDiab). Med J Aust 178, 427-432.

7. Blass EM, Anderson DR, Kirkorian HL, Pempek TA, Price I \& Koleini MF (2006) On the road to obesity: television viewing increases intake of high-density foods. Physiol Behav 88, 597-604.

8. Jeffery RW \& French SA (1998) Epidemic obesity in the United States: are fast foods and television viewing contributing? Am J Public Health 88, 277-280.

9. French SA, Harnack L \& Jeffery RW (2000) Fast food restaurant use among women in the Pound of Prevention study: dietary, behavioural and demographic correlates. Int J Obes Relat Metab Disord 24, 1353-1359.

10. Jeffery RW, Baxter J, McGuire M \& Linde J (2006) Are fast food restaurants an environmental risk factor for obesity? Int J Behav Nutr Phys Act 3, 2.

11. Hill J \& Radimer K (1997) A content analysis of food advertisements in television for Australian children. Aust J Nutr Diet 54, 174-181.

12. Neville L, Thomas M \& Bauman A (2005) Food advertising on Australian television: the extent of children's exposure. Health Promot Int 20, 105-112.

13. Smith A, Kellett E \& Schmerlaib Y (1998) The Australian Guide to Healthy Eating. Canberra: Commonwealth Department of Health and Family Services.

14. World Health Organization (2000) Obesity: Preventing and Managing the Global Epidemic. Report of a WHO Consultation. WHO Technical Report Series no. 894. Geneva: WHO.

15. Australian Bureau of Statistics (2001) Socio-economic Indexes for Areas. Catalogue no. 2039.0. Canberra: Australian Bureau of Statistics.

16. Australian Bureau of Statistics (2003) Population by Age and Sex, Australian States and Territories - 2001 Census Edition: Final. Catalogue no. 3201.0. Canberra: Australian Bureau of Statistics.
17. Australian Film Commission (2003) Get the picture. http:// www.afc.gov.au/GTP?wftvviewtimeofday.html (accessed December 2006).

18. Borzekowski DLG \& Robinson TN (2001) The 30-second effect: an experiment revealing the impact of television commercials on food preferences of preschoolers. $J \mathrm{Am}$ Diet Assoc 101, 42-46.

19. Andrews RL \& Franke GR (1991) The determinants of cigarette consumption: a meta-analysis. J Public Policy Marketing 10, 81-100.

20. Palta M, Prineas RJ, Berman R \& Hannan P (1982) Comparison of self-reported and measured height and weight. Am J Epidemiol 115, 223-230.

21. Booth ML, Hunter C, Gore CJ, Bauman A \& Owen N (2000) The relationship between body mass index and waist circumference: implications for estimates of the population prevalence of overweight. Int J Obes Relat Metab Disord 24, 1058-1061.

22. Spencer EA, Appleby PN, Davey GK \& Key TJ (2002) Validity of self-reported height and weight in 4808 EPIC-Oxford participants. Public Health Nutr 5, 561-565.

23. Australian Divisions of General Practice (2003) Healthy lifestyles must include junk food ad ban. http://www. adgp.com.au/client_images/6261.pdf (accessed January 2004).

24. Mehta K (2002) TV food advertising does not support children's nutrition and health. Paper presented at the NSW Childhood Obesity Summit. http://www.health.nsw. gov.au/obesity/adult/summit/pres/Speech_KayeMehta.pdf (accessed January 2004).

25. Morton LM, Cahill J \& Hartge P (2006) Reporting participation in epidemiologic studies: a survey of practice. Am J Epidemiol 163, 197-203.

26. Curtin R, Presser S \& Singer E (2005) Changes in telephone survey nonresponse over the past quarter century. Public Health Q 69, 87-98. 